\title{
A TRAJETÓRIA DE MULHERES DE SUCESSO NA ÁREA EMPRESARIAL: UMA PERSPECTIVA DE GÊNERO
}

\author{
THE PATH OF SUCCESSFUL WOMEN IN BUSINESS: A GENDER \\ PERSPECTIVE
}

\begin{abstract}
Caroline Cecchin Momesso
Discente do Instituto Federal de Educação, Ciência e Tecnologia de São Paulo (IFSP) câmpus Birigui, Brasil

E-mail: carolbirigui2011@gmail.com

Renato Kendy Hidaka Professor de Sociologia e Sociologia da Educação do Instituto Federal de Educação, Ciência e Tecnologia de São Paulo (IFSP) - câmpus Birigui, Membro Núcleo de Estudos sobre Gênero e Sexualidade do

IFSP (NUGS), Brasil

E-mail: rkhidaka@ifsp.edu.br
\end{abstract}

Recebido: 13/03/2021 - Aceito: 13/03/2021

\section{Resumo}

Não obstante as lutas por igualdade e justiça praticadas por muitas mulheres ao longo da história e dos avanços conquistados relacionados à sua promoção e proteção, a desigualdade de gênero ainda persiste enquanto realidade. Esta pesquisa, partindo da perspectiva de gênero, tem como objetivo examinar a trajetória de quatro mulheres, de diferentes origens e contextos históricos, que alcançaram sucesso profissional dentro da área empresarial, sendo elas: Barbe-Nicole Ponsardin (1777-1866), Madam C. J. Walker (1867-1919), Sheryl SandBerg (1969-) e Luiza Helena Trajano (1951-). Para isso, serão coletados dados, por meio de levantamento bibliográfico, relacionados à trajetória pessoal e profissional das personalidades selecionadas bem como acerca do contexto histórico no qual elas se inscrevem. A pesquisa utiliza como marcador dados referentes à desigualdade de gênero característicos de cada contexto vivido, assim como os depoimentos encontrados nas biografias disponíveis sobre essas mulheres empresárias acerca das dificuldades profissionais que cada uma delas enfrentou relacionadas à condição de ser mulher.

Palavras-chave: Mulheres; Gênero; Desigualdade; Empresárias.

\section{Abstract}

Although the struggles for equality and justice practiced by women throughout history and the advances related to their promotion and protection, gender inequality still persists as a reality. This research, from a gender perspective, aims to examine the trajectory of four women, from different backgrounds and historical contexts, who achieved professional success in the business area, namely: Barbe-Nicole Ponsardin (1777-1866), Madam C. J. Walker (1867-1919), Sheryl SandBerg 
(1969-) and Luiza Helena Trajano (1951-). For this intent, the data will be collected through bibliographic survey, correlating personal and professional trajectory of this selected personalities, including the historical context they are enrolled. This research uses as a boundary the data referring to gender inequality related to each context lived and the testimonies found in this entrepreneurs women's biographies about the professional difficulties that each one faced related to the condition of being a Woman.

Keywords: Women; Genre; Inequality; Business women.

\section{Introdução}

Há séculos que as mulheres vêm lutando por direitos e por um tratamento mais igualitário e justo em relação à condição dos homens. Todavia, a desigualdade de gênero ainda é uma realidade fortemente presente na atualidade. Por desigualdade de gênero, compreendemos, partindo da definição de Giddens (2005, p. 107), "a diferença de status, poder e prestígio que as mulheres e os homens apresentam nos grupos, nas coletividades e nas sociedades". Em quase todas as formações sociais, o marcador de gênero constitui-se como um fator significativo na configuração da estratificação social, na medida em que a situação de gênero está amplamente relacionada às oportunidades sociais, políticas e econômicas que os indivíduos dispõem no interior das mais diversas instituições sociais (GIDDENS, 2005). De acordo com Biroli (2018), a situação de gênero também se relaciona com a divisão sexual do trabalho, que implica na conformação de hierarquias de gênero e na produção de identidades, de vantagens e de desvantagens, como no acesso a postos de trabalho, escolarização e profissionalização. A desigualdade de gênero se consolida e se expressa em "dificuldades cotidianas que vão conformando trajetórias, possibilidades diferenciais na vida de mulheres e homens." (BIROLI, 2018, p. 21).

No Brasil, as estatísticas sobre questões de gênero nos oferecem dados bastante curiosos. No que se refere aos níveis de instrução, as mulheres apresentam, em média, um nível superior ao dos homens. A esse respeito, a maior diferença percentual por sexo encontra-se no nível daqueles que possuem ensino superior completo. Entre as pessoas da faixa etária de 25 a 44 anos, conforme os dados da Pesquisa Nacional por Amostra de Domicílios Contínua, realizada em 
2016, as mulheres correspondem a um total de $21,5 \%$, enquanto os homens 15,6\%. (IBGE, 2018).

Logo, poderíamos perguntar: se a maior parte da população com ensino superior completo é constituída por mulheres, por que, então, elas não ocupam majoritariamente os postos mais elevados na hierarquia do trabalho, como na administração de empresas? O que explica o fato de o campo empresarial ser composto dominantemente por homens?

Continuemos com mais alguns dados. A pesquisa do IBGE supracitada aponta que, diferentemente dos índices sobre escolarização, tanto os postos de liderança no setor privado quanto no setor público são dominantemente ocupados por homens. No setor público, mais especificamente no campo político, essa pesquisa mostra que apenas $16 \%$ dos senadores eram do sexo feminino. $\mathrm{Na}$ Câmara dos Deputados, a representatividade era ainda menor, sendo de 10,5\%. No setor privado, a desigualdade também é evidente. Dos cargos de gerência no setor, $60,9 \%$ são ocupados por homens, enquanto $39,1 \%$ são ocupados por mulheres.

Sabe-se que em uma empresa existem uma variedade de cargos que se distribuem de forma hierárquica. Os cargos executivos são os mais elevados na hierarquia, e apresentam geralmente os melhores salários. Os executivos são os responsáveis pelas decisões mais importantes da empresa e requerem uma formação com um profundo conhecimento acerca de sua área. Como nos ensinam os manuais contemporâneos de administração, o Chief Executive Officer (CEO) é principal chefe da empresa e responsável pelo progresso da mesma, o Chief Financial Officer (CFO) é o responsável pelo controle de recursos financeiros, o Chief Marketing Officer (CMO) é o responsável pelo marketing e o Chief Information Officer (ClO), o responsável pelo sistema de informações da empresa, bem como o armazenamento de dados. Estes cargos executivos são majoritariamente ocupados por homens. Ademais, é extremamente difícil encontrar uma mulher que seja proprietária de uma empresa, entre outras coisas, devido ao fato de que a capacidade de uma mulher ser sempre questionada, principalmente quando esta capacidade se relaciona ao mundo dos negócios. (BLUE PRINTT, 2018). 
Portanto, a partir dos dados apresentados anteriormente, é possível perceber que independente da formação e da competência de uma mulher, os cargos mais elevados no mundo do trabalho são privilégio dos homens. Registrese, contudo, que as mulheres se dedicam não somente aos seus empregos, como também muitas operam em "jornadas duplas", ou seja, além de seus empregos elas também se responsabilizam com o cuidado de sua família e os afazeres domésticos. A pesquisa do IBGE mencionada mostra que as mulheres brancas trabalham em média 17,7 horas semanais em afazeres domésticos e/ou no cuidado de pessoas, enquanto os homens apenas 10,4 horas semanais. A discrepância ocorre também com base no marcador de cor. Comparado a uma mulher branca que dedica 17,7 horas semanais para afazeres domésticos e/ou no cuidado de pessoas, uma mulher negra ou parda dedica, em média, 18,6 horas semanais.

De acordo com o Índice Global de Diferença de Gênero 2021, desenvolvido pelo Fórum Econômico Mundial (WEF), que utiliza como critérios a participação econômica e as oportunidades, a realização educacional, dado sobre saúde e sobrevivência e empoderamento político, dentre 153 países que participaram da pesquisa, o Brasil ocupa o $92^{\circ}$ lugar (WEF 20202), tendo progredido três posições em comparação ao relatório de 2018. Apesar desse progresso, o Brasil possui um dos índices mais elevados de desigualdade de gênero da América Latina, estando em $22^{\circ}$ lugar em um total de 25 países.

Assim sendo, a partir de todos esses dados apresentados é possível observar a dificuldade que as mulheres encontram para conseguir um emprego com um salário e reconhecimento equivalente ao dos homens. Essa dificuldade aumenta ainda mais se a mulher almeja ocupar um cargo elevado, espaço em que a diferença de oportunidades aparece de forma mais marcante, independente da formação da mulher.

Em muitas culturas, as mulheres desde pequenas são desencorajadas a serem protagonistas. Há muitas vezes a divisão implícita do trabalho, sendo as funções intelectuais e de prestígio social e econômico destinadas aos homens e as funções de submissão e menor prestígio, como de assistente, atendente, cuidadora, professora primária etc., destinados às mulheres (BOURDIEU, 2014). Esses dados, somados e articulados a outros, mostram a importância de pesquisas 
que se debrucem sobre os fatores que levaram a algumas mulheres a conseguir ascender a postos elevados no campo empresarial, assim como pesquisas que evidenciem as dificuldades que estas mulheres tiveram que enfrentar em um campo marcado pela dominação masculina.

\section{Metodologia}

Com base nas observações acima, esta pesquisa teve como objetivo geral examinar a trajetória socioprofissional de algumas personagens femininas que tiveram destaque no campo empresarial, situadas em diferentes contextos sociais e históricos, a partir de uma compreensão sociológica que opera sob a perspectiva de gênero. São elas: 1) Barbe-Nicole Ponsardin (1777-1866), empresária francesa do ramo de bebidas, 2) Madam C.J Walker (1867-1919), empresária estadunidense do ramo de cosméticos, 3) Sheryl SandBerg (1969-), empresária estadunidense chefe operacional do Facebook e 4) Luiza Helena Trajano (1951-), empresária brasileira do ramo do comércio de varejo.

Foram objetivos específicos deste trabalho:

1) Analisar a trajetória socioprofissional por trás do sucesso de cada uma dessas quatro mulheres;

2) Comparar as oportunidades e dificuldades relacionadas, na perspectiva da desigualdade de gênero, no que diz respeito à inserção no mundo do trabalho nos diferentes contextos sociais e históricos das respectivas personalidades selecionadas;

3) Identificar, nos depoimentos encontrados nas biografias destas personagens, as dificuldades profissionais que cada uma delas enfrentou concernentes à condição de ser mulher.

\section{Resultados e Discussão}

A partir do que foi proposto, dividimos a apresentação dos resultados obtidos em duas partes. Na primeira, analisamos a trajetória socioprofissional por trás do 
sucesso empresarial de Barbe-Nicole Ponsardin, Madam C.J Walker, Sheryl SandBerg e Luiza Helena Trajano e identificamos as dificuldades profissionais que cada uma delas enfrentou, dando ênfase àquelas relacionadas à condição de ser mulher. $\mathrm{Na}$ segunda parte, fazemos um breve comparativo acerca das oportunidades e dificuldades relacionadas, na perspectiva da desigualdade de gênero, no que diz respeito à inserção dessas mulheres no mundo do trabalho em seus diferentes contextos sociais e históricos.

\subsection{Análise da trajetória socioprofissional das quatro empresárias}

Barbe-Nicole Ponsardin, mais conhecida como a Viúva Clicquot, nasceu em 16 de dezembro de 1777, em Reims, na França, a principal cidade de Champagne. Barbe-Nicole, filha de Nicolas Ponsardin e Jeanne-Clémentine, teve desde a sua infância ótimas condições de vida, crescendo em um ambiente abastado. Nicolas Ponsardin, seu pai, foi um grande empresário ligado à indústria têxtil, o que permitiu à família transitar nos espaços frequentados pela nobreza francesa da época. (PRADO, 2014).

Barbe-Nicole se casou aos vinte anos, com François Clicquot, e ambos receberam como presentes de casamento uma grande fazenda, dois moinhos de ventos e uma boa quantia de dinheiro, de Nicolas Ponsardin, além de um bosque em Quatre-Champs e extensos campos em Tours-sur-Marne e Bisseuil, de Philippe, pai de François Clicquot. (PRADO, 2014).

Entretanto, a vida de Barbe-Nicole Ponsardin mudou completamente quando, em 1805, seu marido faleceu. Mesmo sem nenhuma formação profissional e com uma filha para criar, ela assumiu a empresa de seu falecido marido, aos 27 anos.

Inicialmente, a empresa operava em diversas frentes, abrangendo serviços bancários, o comércio de lã e a fabricação de bebidas. A primeira mudança realizada por Ponsardin foi redirecionar a empresa, voltando-a unicamente para produção de champanhe. (JUSTINO, 2013).

Pouco tempo depois, Ponsardin se destacou no desenvolvimento e no aprimoramento de técnicas de fabricação de champanhe. Em 1810, desenvolveu o 
primeiro champanhe vintage e, em 1816, criou a técnica table de remuage, responsável pela sedimentação de impurezas por meio da colocação das bebidas em uma mesa, denominada pupitre. Dessa forma, os sedimentos da segunda fermentação descem ao topo da garrafa e são mais facilmente retirados, revelando o brilho do champanhe. O table de remuage foi uma técnica inovadora que aumentou ainda mais a popularidade de seus champanhes e é utilizada até hoje. Ponsardin, segundo Suzana Barelli (2018), também foi responsável pela elaboração do primeiro champanhe rosado, em 1818, misturando vinhos tintos. Ademais, a empreendedora francesa sempre demonstrou preocupação quanto aos seus produtos, enviando cartas de reclamação aos locais que não realizassem com acuidade a produção deles.

A competência criadora de Ponsardin muito se deve ao seu interesse pelo trabalho do marido, tendo o acompanhado em diversas de suas viagens de negócio. Some-se a isso: 1) o auxílio de um especialista quando iniciou o comando da empresa, 2) a sua dedicação em buscar o máximo de qualidade em seus produtos e 3) a busca constante de atender as expectativas de seus clientes.

A criatividade de Ponsardin fez com que, paulatinamente, sua empresa adquirisse destaque na sociedade da época. Ela fez suas bebidas serem reconhecidas entre os soldados que batalharam durante a Revolução Francesa, incluindo os estrangeiros que, por sua vez, ajudaram a difundir e propagar a marca quando voltaram aos seus países de origem. (JUSTINO, 2013). Por administrar uma empresa em uma época na qual os homens ocupavam majoritariamente os postos políticos e econômicos mais elevados, Ponsardin teve que se esforçar e lutar contra o machismo prevalecente para ganhar credibilidade no mercado e para que a sua capacidade nos negócios fosse reconhecida.

A lucratividade de sua empresa foi aumentada quando Ponsardin contou com uma grande safra de uvas para a fabricação de seus vinhos, tendo conseguido vendê-los ao término das guerras napoleônicas, em 1815. Foi um salto na exportação de bebidas que passou de quatrocentos mil litros para cinco milhões de litros. Ponsardin, que ficou marcada pelo seu comportamento ousado, vendeu aproximadamente dez mil garrafas de vinho para a Rússia, desrespeitando o bloqueio continental. Teve, inclusive, o reconhecimento e a preferência da 
aristocracia local. O rótulo laranja de suas bebidas foi uma homenagem ao czar russo da época, que tinha a cor laranja como sua cor oficial. Sua empresa se tornou tão famosa que por um bom tempo "chamar a viúva" em festas era o mesmo que pedir champanhe. (JUSTINO, 2013).

Ponsardin faleceu em 1866, mas seu reconhecimento se mantém até os dias atuais. Em 1972, foi criado o Prêmio Veuve Clicquot da Mulher de Negócios. A empresa Veuve Clicquot continua existindo até hoje, sendo integrante do conglomerado LVMH (Louis Vuitton Moët Hennessy). De acordo com a ABS Notícias (2020), atualmente os vinhedos da empresa cobrem quatrocentos hectares que se estendem sobre excelentes áreas de cultivo na província de Champagne, na França.

Devido Ponsardin ter nascido em uma época distante, torna-se difícil o alcance de registros que narrem a sua história, bem como as suas dificuldades, oportunidades e conquistas. A esse respeito, Tilar J. Mazzeo assinala que:

\footnotetext{
No começo do século XIX [...] a vida dos empreendedores e inovadores do comércio raramente entrava nos livros de história. $E$ isso era especialmente verdade se o empreendedor fosse uma mulher. Os arquivos estavam repletos de cartas e diários de príncipes e chefes de Estado, mas poucos bibliotecários pensavam em coletar os registros particulares de comerciantes, mesmo aqueles que fizeram coisas excepcionais [...]. Para uma jovem do século XIX, isso era particularmente verdadeiro, a menos que se tratasse de uma rainha, uma duquesa, a irmã, esposa ou mãe de um grande homem. (2009, p. 10-11)
}

Ainda de acordo com Mazzeo (2009), Barbe-Nicole Ponsardin foi uma mulher de extrema coragem e inteligência ao assumir a empresa após o falecimento de seu marido, mesmo sem ter tido nenhuma experiência ou treinamento. Com sua dedicação, Ponsardin fez a Empresa Veuve Clicquot se tornar uma das mais importantes e prestigiadas casas do champanhe do mundo. Dessa forma, Ponsardin se tornou, aos quarenta anos, uma das mulheres mais ricas e prestigiadas da Europa. Nesse sentido, podemos afirmar que sua importância se dá não apenas no desenvolvimento da produção de champanhes, mas também enquanto exemplo de mulher de negócios, cujo legado serve de incentivo a outras mulheres. Para Mazzeo, Ponsardin "abriu novos horizontes para as mulheres no mundo dos negócios. Sem ter plena consciência do que fazia, 
obrigou as pessoas a sua volta a reconsiderarem os estereótipos de gênero de sua época." (2009, p. 17).

Passemos agora à trajetória de Madam C.J Walker (1867-1919). Sarah Breedlove, mais conhecida como Madame C.J Walker, nasceu em Delta, Luisiana, nos Estados Unidos (EUA), em 23 de dezembro de 1867. Walker sempre passou por dificuldades desde pequena. Criada em uma plantação de algodão e sendo a única filha nascida livre entre seus cinco irmãos - tendo em vista que a abolição da escravidão ocorreu nos EUA em 1863 -, ficou órfã aos sete anos e precisou se mudar para a casa de sua irmã e seu cunhado em Mississipi. Para ajudar nos gastos, trabalhou como empregada doméstica e em uma plantação de algodão. Com apenas quatorze anos, Walker se casou para fugir do ambiente opressivo em que vivia e teve sua primeira e única filha aos dezoito anos, com Moses McWilliams. Dois anos depois, Moses faleceu e Sarah, após um tempo, casou-se novamente, agora com John Davis, tendo seu casamento durado até 1903. (RAMOS, 2020).

Walker então se mudou para o Missouri, onde trabalhou como lavadeira, recebendo US\$ 1,50 por dia (MARASCIULO, 2020). Infelizmente, acabou desenvolvendo uma doença capilar em razão do contato constante com produtos fortes e tóxicos na lavanderia, o que resultou em uma caspa severa e uma forte queda de cabelo. Naquela época, não existia produtos capilares próprios para cabelos enrolados e crespos que pudessem ajudá-la. Seu problema só foi resolvido quando conheceu Annie Malone em uma feira de produtos. Dona do Poro Company, Annie desenvolveu diversos produtos para cabelos tanto enrolados quanto crespos e ajudou Walker a ter seus cabelos novamente. Walker ficou tão feliz com o resultado que por um tempo trabalhou para Annie como sua agente de vendas.

Com o aprendizado recebido de Annie, Walker passou a desenvolver seus próprios produtos capilares, fato que se deu logo após o seu casamento com Charles Joseph Walker, quando então passou a ser conhecida como Madam C.J Walker. (MARASCIULO, 2020). O recém marido de Sarah a auxiliava na publicidade de seus produtos. Ela passou a vendê-los de porta em porta, além de ensinar outras mulheres negras a cuidarem de seus cabelos. Sua empresa 
começou a crescer e Walker a transferiu para Indianópolis, em 1910, onde passou a vender ainda mais cosméticos com o auxílio de várias mulheres negras como agentes de venda. Os negócios só foram aumentando e Walker se tornou milionária, ficando conhecida como a primeira mulher milionária self made dos Estados Unidos, de acordo com o Guinness Book of World Records, com uma fortuna estimada de US\$ 8 milhões, sem ter tido nenhuma formação profissional.

Vale ressaltar que seu relacionamento com Charles J. Walker durou até 1921, mas Sarah continuou sendo conhecida como Madam C. J. Walker, especialmente porque era o nome de sua empresa. Walker faleceu em 1919, com cinquenta e um anos de idade. Todavia, durante a sua vida pode ajudar milhares de mulheres negras, uma vez que chegou a chefiar mais de vinte mil mulheres que ocupavam o cargo de agentes de venda em sua empresa. Walker também utilizou de sua fortuna para beneficiar diversas causas, com doações para bolsa de estudos, casa de idosos e o apoio à instituições voltadas à melhoria da vida dos negros. Suas principais contribuições estão relacionadas à causas feministas e à luta contra o racismo. Ademais, Walker comprou uma mansão em Irvington, Nova York, arquitetada em 1918, por Vertner Tandy, sendo este o primeiro arquiteto negro registrado nos Estados Unidos. Sua mansão foi posteriormente transformada em uma ONG, onde diversas mulheres negras se reúnem e são incentivadas e orientadas a serem bem-sucedidas no campo do empreendedorismo.

A'Lelia Walker, filha de Walker, deu continuidade aos negócios e a empresa perseverou até fechar oficialmente em 1981. Atualmente, Walker ainda é homenageada e lembrada. Em 2016, a Beauty Walker, da Sephora, homenageou a empresa em seu lançamento de cosméticos. Em 2020, a Netflix produziu uma minissérie que narra a história de Walker, intitulada Self Made. Por fim, a tetraneta de Walker, A'Lelia Bundles escreveu vários livros que narram a história de sua trisavó. (R7, 2020)

Em seu trabalho de doutoramento, Giovana Côrtes (2012) afirma que Madam C. J. Walker foi uma mulher que se destacava por sua dedicação e sua defesa de causas sociais. Em seus relatos biográficos, Walker sempre se colocava como uma heroína tão perseverante quanto os homens de sua cor, e comparavase a Frederick Douglass e Paul Laurence Dunbar. 
Walker também foi convidada para falar na convenção NNBL pelo presidente e fundador Booker T. Washington, que a introduziu como "uma das mais progressistas e famosas mulheres da nossa raça". (CÔRTES, 2012).

Além de contribuir, principalmente, à causas que ajudassem os negros e de se posicionar contra o preconceito, Walker também realizou diversos discursos nos quais narra a sua história e as suas dificuldades como uma mulher negra filha de escravos. Em um discurso proferido na National Negro League Business Convention, em 1912, relatou:

Eu sou uma mulher que veio dos campos de algodão do Sul. Lá, fui promovida ao tanque de lavar roupa [e depois] à cozinha. [Da cozinha] eu me autopromovi ao mundo empresarial dos manufaturados e preparações para o cabelo [e assim] eu construí minha própria empresa, no meu próprio chão. (CÔRTES, 2012, p. 17).

Em uma entrevista para a New York Times magazine, em novembro de 1917, Walker também relatou:

Eu fui para Denver, Colorado e comecei minha carreira com um capital de $\$ 1,25$. Comecei, é claro, de uma forma mais modesta. Sondava as pessoas da minha raça indo de porta em porta. Depois disso, fui muito bem. Mas, claro, encontrei muitos obstáculos antes de finalmente alcançar o verdadeiro sucesso. Eu não acredito em ganhar chances. Nunca peguei uma num estoque de supermercado. Não sou uma milionária, mas espero ser um dia, não por causa do dinheiro, mas porque poderei fazer muito para ajudar minha raça. (CÔRTES, 2012, p. 329).

Portanto, podemos dizer que Madam C. J Walker foi um exemplo de protagonismo e empoderamento feminino. Além de ter desenvolvido produtos capilares próprios para os cabelos cacheados e crespos, ter criado e desenvolvido uma empresa de forma autônoma e ter lucrado o suficiente para ser considerada a primeira mulher negra milionária dos Estados Unidos, ela também enfrentou as restrições e os desafios impostos à condição de ser mulher e negra em seu contexto sócio-histórico.

Passemos agora à trajetória de Sheryl Kara Sandberg. Mais conhecida como Sheryl Sandberg, nasceu na cidade de Washington D.C., capital dos Estados Unidos, em 28 de agosto de 1969. Sua habilidade para o mundo dos negócios e 
inteligência podem ser notadas desde a sua formação profissional. Sandberg se formou em economia na Harvard, em 1991, e sempre se destacou como aluna, recebendo a honraria de ser a melhor estudante da turma. Participou do projeto Women in Economics and Government (mulheres na economia e no governo), o que the rendeu uma vaga de pesquisadora no Banco Mundial (BM) assim que ela se formou. No BM, contribuiu com projetos relacionados aos problemas de saúde na Índia, juntamente com seu ex-orientador, Lawrence Summers, que na época era o economista-chefe do BM. Também ganhou uma bolsa de estudos para realizar seu MBA, em Harvard, enquanto trabalhava como consultora da McKinsey \& Company. (SUNO RESEARCH, 2018).

Após um ano, Sandberg deixou seu emprego como consultora e foi trabalhar no departamento do Tesouro dos Estados Unidos, novamente junto com Lawrence Summers, que havia sido nomeado como secretário do Tesouro, no governo de Bill Clinton. Sandberg trabalhou como chefe da equipe de Summers com menos de 30 anos. (ÉPOCA, 2011).

Em 2001, deixou seu cargo e ingressou na Google. Sua carreira ganhou mais destaque ainda, visto que ela era responsável pelas vendas on-line de produtos e iniciou coordenando uma equipe de quatro pessoas e, um pouco antes de sair do emprego, liderava aproximadamente quatro mil funcionários. Sandberg ingressou na Google na época em que os serviços da empresa passaram a ser cada vez mais utilizados. De acordo com a revista Época (2011), como vicepresidente de operações, ela foi umas das responsáveis pela criação do sistema de publicidade do buscador que, em 2011, gerou em torno de US\$30 milhões.

A decisão de sair da Google e começar a trabalhar como COO no Facebook, em 2008, que na época não tinha o mesmo destaque e lucratividade que hoje em dia, foi uma escolha bem difícil. Sheryl era e ainda é responsável pelas operações de políticas públicas, vendas, marketing, desenvolvimento de negócios, recursos humanos e comunicações. Contudo, seu objetivo principal na época era descobrir uma forma de monetizar a rede social. O resultado foi a criação do Social Ads, que apresenta anúncios ligados ao perfil do usuário ou indicações de anúncios de interesse de seus amigos. 
Sandberg fez parte do crescimento e da lucratividade que a empresa adquiriu no decorrer dos anos. Sua atuação profissional rendeu-lhe uma cadeira no conselho da Facebook, sendo ela a primeira mulher integrante do grupo. (SUNO RESEARCH, 2018).

Ela também trabalha, além de $\mathrm{COO}$ da Facebook, como conselheira da Disney Company. (SUNO RESEARCH, 2018). Prova de seu reconhecimento, Sandberg já esteve na lista das cem pessoas mais importantes da New York Times e entre as cinquenta mulheres de mais destaque da revista Fortune e do The Wall Street Journal.

Por fim, vale ressaltar que Sandberg também é co-fundadora e presidente do conselho de uma plataforma chamada Lean in. Nesta plataforma há um grupo formado por diversas mulheres, incluindo Sheryl, que buscam auxiliar e incentivar as mulheres que querem cargos antes priorizados aos homens, como a chefia de uma empresa, por exemplo. Segundo elas:

\begin{abstract}
Queremos um mundo onde pessoas de todos os sexos possam perseguir seus sonhos sem preconceitos ou outras barreiras que os impeçam. Onde as meninas crescem e se tornam líderes confiantes e resilientes. Onde mais mulheres dirigem empresas e países. Somos movidos pela crença de que nossa sociedade e economia seriam melhores se mulheres e meninas fossem avaliadas como iguais a homens e meninos. ${ }^{1}$
\end{abstract}

Sandberg é uma mulher que se destacou logo cedo, desde seus anos escolares. Contudo, vale ressaltar o quanto é difícil uma mulher conseguir alcançar um cargo elevado dentro de uma empresa. A esse respeito, SandBerg afirma que as mulheres se sentem desmotivadas a lutarem pela obtenção de uma posição mais alta na hierarquia de uma empresa por medo de não conseguirem, devido a necessidade de cuidar dos filhos e por não acreditarem no próprio potencial. Por isso, ela incentiva as mulheres a arriscarem. De acordo com Sandberg, é somente arriscando, buscando conciliar emprego e família, que se torna possível saber se o resultado será o esperado ou não. (EL PAís, 2015)

\footnotetext{
${ }^{1}$ Ver: NOSSA missão. Lean in. Disponível em: <https://leanin.org/about>.
} 
Sobre a desigualdade de gênero, Sandberg aponta que "quando um menino se mostra forte, é chamado de líder; quando é menina, é mandona". (EL PAís, 2015, on-line).

Uma das admiradoras de Sheryl, a advogada e banqueira de investimentos em Londres, Miranda Brawn, diz:

\begin{abstract}
Não é nenhum segredo que as mulheres em todo o mundo têm dificuldade para ascender por várias razões. Modelos como Sandberg estão mudando isso. Ela subiu na carreira, mas também defendeu constantemente os direitos das mulheres trabalhadoras no escritório e em casa. [...] Sandberg fala muitas vezes de como as mulheres líderes são menos apreciadas do que seus colegas do sexo masculino e como a falta de confiança em si mesmas é seu maior obstáculo. Ela acredita que as pessoas têm de se sentir confortáveis com mulheres líderes, inclusive as próprias mulheres. Não é apenas uma executiva em uma grande empresa; é uma verdadeira líder. [...] Não acredito que a mensagem seja que é necessário ascender acima de tudo, mas que saibamos que podemos. (EL PAís, 2015, on-line)
\end{abstract}

Sandberg também afirma em seu livro que, apesar da conquista de mais espaço no mercado e da melhora em sua condição mais geral, ainda a igualdade entre homens e mulheres não foi realmente alcançada. Em suas palavras:

[...] a verdadeira igualdade está longe e só será alcançada quando um número maior de mulheres subir ao topo de todos os governos e de todos os setores da economia. Posto isso, temos de trabalhar arduamente para chegar lá. Todos nós, homens e mulheres, temos de entender e reconhecer que os estereótipos e as discriminações toldam nossas convicções e perpetuam o status quo. Em vez de ignorar nossas diferenças, precisamos aceitá-las e superá-las. (SANDBERG, 2013, p. 197)

Portanto, Sandberg é um exemplo de como as mulheres podem ser capazes ocupar uma posição elevada em determinada empresa sem perder a capacidade executar seus compromissos familiares. Sandberg possui dois filhos e concilia trabalho e família.

Passemos agora à trajetória de Luiza Helena Trajano Inácio Rodrigues, mais conhecida como Luiza Helena Trajano. Luiza nasceu no dia 9 de outubro de 1951, em Franca, no interior do estado de São Paulo, Brasil. Desde os 12 anos, durante o período de suas férias escolares, ela ajudava os tios, Pelegrino José Donato e 
Luiza Trajano Donato, em sua loja, local onde posteriormente viria a ser o famoso Magazine Luiza. Inicialmente era um pequeno empreendimento, chamado $A$ Cristaleira, que se ocupava da venda de pequenas lembranças. Foi inaugurado em 16 de novembro de 1957. A loja só viria a ser conhecida como Magazine Luiza quando Luiza Trajano Donato fez um concurso para escolher o nome da loja na rádio de Franca, e o resultado foi Magazine Luiza em sua homenagem.

Luiza Helena Trajano se formou na Faculdade de Direito de Franca (FDF) e gradativamente foi subindo de posto na loja de seus tios, onde só foi assumir a liderança da empresa em 1991. (LUIZA, 2018).

Desde o início de sua presidência, Luiza efetuou diversas mudanças na empresa, como a criação das Lojas Virtuais, uma forma de venda utilizada até hoje que se caracteriza pela compra por meio virtual em uma unidade da rede de forma a obter um produto que ainda não estava no estoque da unidade. Luiza também criou "A Liquidação Fantástica", que ocorre todos os anos no mês de janeiro, logo após a virada do ano, e que corresponde a um desconto de até $70 \%$ na compra de qualquer produto da loja. (NOSSA, 2020).

No decorrer dos anos a rede só foi ampliando cada vez mais e no ano de 2015 já estava com setecentas e oitenta e cinco lojas em dezesseis estados do Brasil. O Magazine também comprou outras redes concorrentes, como as lojas Líder, de Campinas (SP), e a Arno, do Rio Grande do Sul (RS). ${ }^{2}$

A rede Magazine Luiza ganhou diversas premiações. No ano de 2017, foi considerada como uma das dez mais inovadoras da América Latina, de acordo com a Fast Company. Além disso, pelo décimo nono ano seguido a Magazine foi também considerada como uma das melhores empresas do Brasil para se trabalhar, estando em $4^{\circ}$ lugar, de acordo com o Instituto Great Place to Work. Luiza Helena Trajano também já esteve no grupo de "Mulheres Mais Poderosas do Brasil”, conforme a Forbes (PRÊMIOS, 2020). ${ }^{3}$

\footnotetext{
2 Ver: NOSSA história. Magazine Luiza. Disponível em: <https://ri.magazineluiza.com.br/ShowCanal/NossaHistoria?=itcqcsmNR6yfJoCokxfmsg==>.

3 Ver: PRÊMIOS e reconhecimentos. Magazine Luiza. Disponível em: $<$ https://ri.magazineluiza.com.br/ShowCanal/Premios-eReconhecimentos?=Z7pywmj5YSW3wFVsMAhgAw==>.
} 
Em 2019, a empresa lucrou com suas vendas totais cerca de 27,3 bilhões de reais. ${ }^{4}$ Trajano realiza diversas palestras nas quais apresenta lições e dicas de como crescer com uma empresa e obter sucesso nos negócios. Nessas palestras, também incentiva o protagonismo e o empoderamento feminino, principalmente na área da administração e do empreendedorismo. De acordo com o site Suno Research (2018), Luiza faz parte do Grupo Mulheres do Brasil que é formado por diversas mulheres que atuam nos mais variados segmentos da economia do país.

Conforme dados extraídos do site da loja, um dos diferenciais da Magazine Luiza é a preocupação com os funcionários e clientes. Luiza incluiu um disk denúncia no site oficial da loja para que as mulheres, incluindo suas funcionárias, possam pedir ajuda caso estejam sofrendo violência doméstica. Além disso, a rede possui um programa de incentivo à inclusão de deficientes, contando com mais de mil pessoas, segundo informações de 2015 (MENSAGEM, 2020). Também recentemente promoveu um programa de trainees específico para candidatos negros (UOL, 2020).

Trajano também afirmou em uma entrevista para o Uol (2019) que acredita que a figura feminina deve estar mais presente em empresas, principalmente em posições elevadas na hierarquia do trabalho. Em suas próprias palavras:

\begin{abstract}
Hoje nós temos $7 \%$ de mulheres em conselhos [de empresas]. Se você tirar as donas e filhas de donas, como eu, cai para $4 \%$. Está provado que os países que colocaram cotas para mulheres nos conselhos aumentaram seu PIB [Produto Interno Bruto] e o lucro. O que estamos lutando é para termos $30 \%, 40 \%$. Como está, levará cem anos para ter $20 \%$ ou $30 \%$. E não estou lutando por mim, porque sou dona, vou estar no meu conselho. Estou lutando pela executiva que trabalhou, que pode trocar experiência hoje, mas é o homem que vai para os conselhos [de empresas], e a mulher tem que guardar essa experiência na gaveta. Não queremos tirar os homens, queremos ter $30 \%$ de mulheres. (Matias, 2019, on-line)
\end{abstract}

No prefácio à edição brasileira no livro de Sheryl Sandberg (2013), Luiza afirma que, por ter nascido em um ambiente familiar com mulheres empreendedoras, foi encorajada, desde criança, a liderar e não sofreu, relativamente, tanto preconceito por ser uma mulher. Também aponta que sempre

\footnotetext{
${ }^{4}$ Cf. QUEM somos. Magazine Luiza. Disponível em: <https://ri.magazineluiza.com.br/ShowCanal/QuemSomos?=urUqu4hANIdyCLgMRgOsTw==>.
} 
foi uma boa mãe, mas que muitas vezes seu marido assumia parte das responsabilidades domésticas para que ela pudesse focar em seu trabalho. Segundo Trajano, uma mulher deve ter a opção de escolher focar em sua carreira e isso não a tornará uma péssima mãe. Contudo, alguns outros fatores influenciam neste caso, como Trajano aponta:

\begin{abstract}
É bom lembrar também que no Brasil, onde a desigualdade social é muito maior que nos Estados Unidos, a maioria das mulheres não pode se dar ao luxo de fazer essa escolha. Muitas delas são responsáveis pelo sustento da família. Na classe operária, esse é o caso de $60 \%$ das brasileiras, que, além da culpa, têm que enfrentar problemas como transporte público ineficiente e ausência de creches. A falta de estrutura e de apoio a essa mãe limita seu desenvolvimento profissional [...]. (SANDBERG, 2013, p. 11-12)
\end{abstract}

Conforme Matias (2019), Trajano se considera feminista, afirmando que durante sua trajetória passou por momentos desconfortáveis quando se mudou para São Paulo, nos quais julgavam a sua capacidade por ser mulher e oriunda do interior, tendo inicialmente um vocabulário e um modo de se vestir que não agradavam os paulistanos, mas afirma que mesmo assim seguiu adiante acreditando em seu próprio potencial. Como descreve no trecho:

Agora vamos falar do feminino. Sempre lutei muito para ser feminina na minha administração. Ainda hoje sou a única mulher no meio de muitos homens. [...] Por um período, foi mais difícil porque era uma época de reengenharia, uma época de práticas muito masculinas, e eu estava no contraponto. Por outro lado, era uma empresa muito mecânica. Quando falava de pessoas, no varejo principalmente, falavam que eu era piegas, que era coisa do interior, é mimimi, não ia durar nada. (MATIAS, 2019, online)

Portanto, Luiza mostra que, independentemente de julgarem ou não a capacidade de uma mulher, esta deve seguir em frente com seus projetos e acreditar em si mesma, buscando provar para outros e para ela própria que também é capaz tanto quanto um homem poderia ser.

\title{
5. Conclusão
}


Ao compararmos a trajetória das quatro mulheres estudadas, podemos observar e diferenciar as oportunidades e dificuldades que cada uma vivenciou em seu percurso socioprofissional. Quando analisamos a trajetória das duas mulheres que viveram em épocas mais distantes da atual, observamos, relativamente, o maior impacto das relações sociais de dominação masculina em suas trajetórias socioprofissionais, especialmente, no que concerne às dificuldades que enfrentaram. Ponsardin vivenciou o contexto sociocultural da Revolução Francesa (1789-1799), fato que levou à conquista, pelos homens, de direitos políticos como cidadãos. No entanto, as mulheres que lutaram ao lado deles não. Não chegou a vivenciar a Primeira Onda do Feminismo, que viria a acontecer apenas no final do século XIX. (SIQUEIRA; BUSSINGUER, 2020).

Ademais, apesar de Ponsardin ter sido uma mulher na administração de uma empresa, sua condição de classe permitiu com que ela herdasse capital econômico de seus familiares, na forma de bens e empresas, além de ter adquirido conhecimento sobre o ramo quando acompanhava seu marido em suas negociações e viagens de trabalho e ter sido auxiliada por um especialista, quando assumiu os negócios da família. Apesar de contar com esses elementos diferenciais, Ponsardin ainda teve que lutar pelo crescimento e reconhecimento de sua empresa, já que, por ser uma mulher na chefia, sua capacidade administrativa era constantemente questionada.

Já Madam C.J Walker (1867-1919), uma mulher negra filha de escravos que se tornou órfã aos sete anos, viveu em época que, assim como Ponsardin, era baseada no machismo estrutural, no patriarcalismo e, ainda, no racismo. Walker nasceu após a abolição da escravidão nos EUA, mas isso não significou que as condições de trabalho eram favoráveis aos negros. Walker vivenciou a Primeira Onda do Feminismo, marcada pela luta das mulheres pelo direito ao voto, à educação e à vida pública e privada. Entretanto, nesse momento, a causa privilegiava as mulheres brancas da classe média, deixando de lado as mulheres operárias e principalmente as negras. Walker teve que passar por inúmeras dificuldades até alcançar o auge nos negócios, ou seja, até se tornar um exemplo para outras mulheres negras e, assim, contribuir para a causa feminista. Vale ressaltar que Walker, dada a sua condição de classe naquele contexto, não teve 
nenhuma formação profissional ou privilégios, como Ponsardin teve. (SIQUEIRA; BUSSINGUER, 2020).

Comparando, agora, as outras duas mulheres que se inserem em contextos mais atuais podemos notar uma diminuição quanto às dificuldades vivenciadas em relação à desigualdade de gênero. Luiza Helena Trajano (1951-) e Sheryl Sandberg (1969-) vivenciaram a segunda e terceira onda do feminismo, nas quais gradativamente as mulheres foram conquistando direitos e melhores condições de vida no interior da sociedade, e a inserção crescente das mulheres no mundo do trabalho. Ainda assim, como observamos em seus relatos, Trajano teve sua capacidade questionada diversas vezes ao longo de sua vida em razão de ser uma mulher e oriunda do interior. Mesmo assim, conseguiu chefiar sua empresa e auxilia inúmeras causas sociais, em especial, causas voltadas às demandas feministas e projetos que incentivam mulheres a alcançarem sucesso e inserção profissional. Sandberg, de forma semelhante, também teve inúmeras vezes sua capacidade profissional questionada, mas também conseguiu obter sucesso em sua carreira e ser um exemplo para outras mulheres. Vale ressaltar que tanto Trajano quanto Sandberg fazem parte de um momento histórico no qual as mulheres conquistaram o direito à formação profissional. Trajano, por exemplo, cursou a Faculdade de Direito de Franca (FDF) e SandBerg se formou em Harvard, nos Estados Unidos. (SIQUEIRA; BUSSINGUER, 2020).

Portanto, é possível concluir que ao longo do tempo as mulheres foram conquistando e ampliando direitos e espaços que antes eram exclusivamente masculinos. Essas conquistas são o efeito da atuação coletiva do movimento feminista e da trajetória sociocultural e profissional de inúmeras mulheres que enfrentaram e enfrentam muitos desafios ainda hoje. Desafios que têm levado, inclusive, a reconhecer a diferença de oportunidades no interior do coletivo formado pelas mulheres, visto que, além das desigualdades de gênero, cruzam a vida de muitas delas as desigualdades advindas da cor de sua pele e da sua condição de classe.

Como forma de conclusão, podemos afirmar que, ao longo do tempo, a desigualdade de gênero diminuiu em termos relativos. As dificuldades para uma mulher assumir uma empresa atualmente são bem menores do que nos séculos 
XVIII e XIX, se considerarmos as trajetórias de Ponsardin e Walker. Contudo, ainda assim é visível a discrepância entre os cargos ocupados por mulheres e homens, sendo difícil ver mulheres trabalhando em cargos elevados, como na chefia de um negócio. O julgamento da capacidade de uma mulher por conta de seu gênero, visto nos depoimentos de Trajano e Sandberg, ainda é um fenômeno que permanece existindo. Logo, ao resgatarmos essas trajetórias de sucesso no campo empresarial nosso intuito aqui não era apenas o de estudar histórias singulares de vida de mulheres de destaque - que, tal como compreendemos, merecem ser conhecidas e estudadas -, mas, sobretudo, o de caracterizar os percalços enfrentados e que muitas vezes ainda persistem, em diferentes contextos sóciohistóricos, decorrentes de questões referentes à desigualdade de gênero.

\section{Referências}

290 - DUAS DAMAS DO VINHO E SUAS CRIAÇÕES. Abs Notícias, 2020.

Disponível em: <https://absnoticias.abs-rio.com.br/curiosidade/290-duas-damas-dovinho-e-suas-criacoes/>. Acesso em: 17 de set. de 2020.

A EXECUTIVA do Facebook que quer mais chefas. EI país, 2015. Disponível em: <https://brasil.elpais.com/brasil/2015/08/07/tecnologia/1438945047_003893.html?o utputType=amp $>$ Acesso em: 26 de set. de 2020.

BARELLI, Suzana. Madame Clicquot, a primeira dama do champanhe. Terra, 2018. Disponível em: <https://www.revistamenu.com.br/amp/2018/03/07/madameclicquot-a-primeira-dama-do-champanhe/>. Acesso em: 15 de set. de 2020.

BIROLI, Flávia. Gênero e Desigualdades: os limites da democracia no Brasil. São Paulo: Boitempo, 2018.

BOURDIEU, Pierre. A dominação masculina. Rio de Janeiro: Bertrand Brasil, 2014.

CAPPELLE, M. C. A.; MELO, M. C. O. L.; SOUZA, N. L. Mulheres, Trabalho e Administração. Revista Interdisciplinar de Gestão Social - RIGS, v. 2, p. 161 191, 2013.

CÔRTES, Giovana. Brancas de almas negras?: beleza, racialização e cosmética na imprensa negra pós-emancipação (EUA, 1890-1930). 2012. 424 p. Tese (doutorado) - Universidade Estadual de Campinas, Instituto de Filosofia e Ciências Humanas, Campinas, SP. Disponível em: 
Revista Multidisciplinar do Nordeste Mineiro, v.1,

2021/01

ISSN 2178-6925

<http://www.repositorio.unicamp.br/handle/REPOSIP/280975>. Acesso em: 26 set. 2020.

FERRARI, Bruno. Sheryl Sandberg, a babá de Mark Zuckerberg. Época, 2011.

Disponível em: <http://revistaepoca.globo.com/Revista/Epoca/0,,EMl24959815259,00-SHERYL+SANDBERG+A+BABA+DE+MARK+ZUCKERBERG.html>. Acesso em: 19 de set. de 2020.

GIDDENS, Antony. Sociologia. 4. ed. Porto Alegre: Artmed, 2005.

JUSTINO, Agatha. Barbe-Nicole Ponsardin: a primeira mulher de negócios do século XIX. Administradores, 2013. Disponível em:

$<$ https://administradores.com.br/artigos/barbe-nicole-ponsardin-a-primeira-mulherde-negocios-do-seculo-xix> Acesso em: 15 de set. de 2020.

IBGE. Estatísticas de gênero: indicadores sociais das mulheres no Brasil, 2018. Disponível em:

$<$ https://biblioteca.ibge.gov.br/visualizacao/livros/liv101551_informativo.pdf.>. Acesso em 2 abr. 2020.

LUIZA Helena Trajano - a empresária que comanda o Magazine Luiza. Suno Research, 2018. Disponível em: <https://www.sunoresearch.com.br/tudosobre/luiza-helena-trajano/?amp>. Acesso em: 25 de set. de 2020.

MARASCIULO, Marília. Conheça Madam C.J. Walker, primeira milionária self made negra dos EUA. Galileu, 2020. Disponível em:

$<$ https://revistagalileu.globo.com/amp/Sociedade/Historia/noticia/2020/03/conhecamadam-cj-walker-primeira-milionaria-self-made-negra-dos-eua.html>. Acesso em: 17 de set. de 2020.

MATIAS, Beth. Pare de xingar e reclamar: país vive crise de raiva e xingamento; saída é

parar de lamentar e fazer, diz Luiza Trajano. Uol, 2019. Disponível em:

<https://economia.uol.com.br/reportagens-especiais/entrevista-uol-lideres-luiza-

helena-trajanomagazine-

luiza/\#cover>. Acesso em: 26 set. 2020.

MAZZEO, Tilar J. A Viúva Clicquot: a história de um império do champanhe e da mulher que o construiu. Rio de Janeiro: Rocco, 2009.

MENSAGEM da Luiza. Magazine Luiza. Disponível em:

$<$ https://ri.magazineluiza.com.br/ShowCanal/Mensagem-da-

Luiza?=Jf8aK9KzDiTn7Y+wl5cefg==>. Acesso em: 25 de set. de 2020.

NOSSA missão. Lean in. Disponível em: <https://leanin.org/about> Acesso em: 27 de set. de 2020. 
NASCIMENTO, Talita. Programa de trainees do Magazine Luiza terá apenas candidatos negros. Uol economia, 2020. Disponível em:

<https://economia.uol.com.br/noticias/estadao-conteudo/2020/09/19/programa-detrainees-do-magazine-luiza-tera-apenas-candidatos-

negros.htm?utm_source=facebook\&utm_medium =social-

media\&utm_campaign=noticias\&utm_content=geral\&fbclid=IwAR016XbGEPkgzQX qUz41f8BfsVDcZExzDYsdPeiTysq2JzRttivlv4vzzFg>. Acesso em: 25 de set. de 2020.

NOSSA história. Magazine Luiza. Disponível em:

$<$ https://ri.magazineluiza.com.br/ShowCanal/Nossa-

Historia?=itcqcsmNR6yfJoCokxfmsg==> Acesso em: 25 de set. de 2020.

ODI - Overseas Development Institute. 10 Things To Know About The Global

Labour Force 2017 [Informativo via pdf disponível na Internet] Acesso em: 2 abr. 2020. Disponível em: <https://www.odi.org/sites/odi.org.uk/files/resourcedocuments/11427.pdf>. Acesso em 4 abr. 2020.

PERFIL da chefe operacional do Facebook. Suno Research, 2018. Disponível em: <https://www.sunoresearch.com.br/tudo-sobre/sheryl-sandberg/?amp>. Acesso: 19 de set. de 2020.

PRADO, Cristina A. VEUVE Clicquot, a grande dama da Champagne.

Sommelière, 2014. Disponível em: <https://sommeliere.com.br/2014/07/31/veuveclicquot-a-grande-dama-de-champagne/>. Acesso em: 25 set. de 2020.

PRÊMIOS e reconhecimentos. Magazine Luiza. Disponível em:

$<$ https://ri.magazineluiza.com.br/ShowCanal/Premios-e-

Reconhecimentos?=Z7pywmj5YSW3wFVsMAhgAw==> Acesso em: 25 de set. de 2020.

QUEM somos. Magazine Luiza. Disponível em:

$<$ https://ri.magazineluiza.com.br/ShowCanal/Quem-

Somos?=urUqu4hANIdyCLgMRgOsTw==> Acesso em: 25 de set. de 2020.

RAMOS, Gustavo. Madam C.J. Walker - História, trajetória e adaptação. Segredos do mundo, 13 de mai. de 2020. Disponível em:

$<$ https://segredosdomundo.r7.com/madam-c-j-walker/>. Acesso em: 17 de set. de 2020.

SANDBERG, Sheryl. Faça Acontecer: mulheres, trabalho e a vontade de liderar. $1^{\underline{a}}$ ed. São Paulo: Companhia das Letras, 2013.

SIQUEIRA, Carolina B.; BUSSINGUER, E. C. A. As ondas do feminismo e seu impacto no mercado de trabalho da mulher. Revista Thesis Juris, v. 9, p. 145-166, 2020 
Revista Multidisciplinar do Nordeste Mineiro, v.1,

SOUZA, E. M.; CORVINO, M. M. F.; LOPES, B. C. Uma análise dos estudos sobre o feminino e as mulheres na área de administração: a produção científica brasileira entre 2000 a 2010. Organizações \& Sociedade (Online), v. 20, p. 603-621, 2013.

STEARNS, Peter N. História das relações de gênero. São Paulo: Contexto: 2007.

SUSTENTABILIDADE. Magazine Luiza. Disponível em:

<https://ri.magazineluiza.com.br/ShowCanal/Sustentabilidade?=hNCv6vApqpAL+O XvnL9M7A==>. Acesso em: 25 de set. de 2020.

WORLD Economic Forum. Selected Country Performances 2020 [relatório disponível na internet]. Disponível em: <http://reports.weforum.org/global-gendergap-report-2020/the-global-gender-gap-index-2020/selected-countryperformances/>. Acesso em 2 de abr. de 2020.

. Global Results 2020 [relatório disponível na internet]. Disponível em: <http://reports.weforum.org/global-gender-gap-report-2020/the-global-gendergap-index-2020/results-and-analysis/>. Acesso em: 02 de fev. de 2021. 